Article

\title{
Analysis of Passenger Incident Data from Five Rail Transit Systems
}

\author{
Katharine Hunter-Zaworski
}

School of Civil and Construction Engineering, Oregon State University, Corvallis, OR 97331, USA; hunterzk@oregonstate.edu; Tel.: +1-541-737-4982

Received: 12 January 2017; Accepted: 11 September 2017; Published: 12 September 2017

\begin{abstract}
The study results reported here are part of a larger research project that developed a manual for practitioners to improve safety at rail transit platform/train and platform/guideway interfaces. As part of that effort, passenger injury incident data was collected from five rail transit systems, and interviews were conducted with safety officers at other rail transit systems in the US and Canada. The data collected showed that stairs and escalators and general platform tripping produced more injury incidents than the platform/train and platform/guideway interfaces. Heavy rail transit with platforms that are higher than 24 inches from top of rail had more injury incidents than light rail transit that typically operates on low level platforms. Other causes of injury incidents included intoxication, attempted suicide, and distraction.
\end{abstract}

Keywords: platform/train platform/guideway interface; incidents; passenger rail safety

\section{Introduction}

The objective of the research was to collect and analyze injury incident data for a research project that entailed the development of a manual for practitioners to improve safety at rail transit platform/train and platform/guideway interfaces. The manual provides treatment strategies to prevent incidents and improve safety at platform/train and platform/guideway interfaces [1]. The research focused on rail transit systems with level or near level boarding where the train floors are level or near level with the platform.

The research showed that the mode of rail transit and the height of the platform from the top of rail were the most significant factors to platform/train and platform/guideway related incidents. Heavy rail transit operating with high level platforms with a height of more than 24 inches from top of rail had more incidents that impacted safety at rail transit stations than streetcars or light rail transit, which typically operate on low level platforms that are 14 inches from top of rail.

\section{Methods}

Safety officers at many rail transit systems were contacted for passenger incident data related to platform/train and platform/guideway incidents. Safety officers from systems that operate light rail or street car systems responded that they did not have any incident data related to the platform/train and platform/guideway interface, however several agreed to be interviewed by the research team.

Many transit agencies are very reluctant to share incident data. The research team contacted many agencies, but incident data was obtained from five rail transit systems in the US that operate heavy rail transit systems. All the rail transit agencies report to the US Federal Transit Administration (FTA) and provide data to the National Transit Database. Commuter rail transit agencies that operate on shared track with freight rail report to the Federal Railroad Administration (FRA). No commuter rail systems supplied any incident data. To protect the identity of the transit systems that willingly provided valuable incident data, each transit system was assigned a letter and is referred to by that 
letter. None of the data provided indicated if the incident resulted in a fatality, serious injury, or minor injury. Only one transit system (A) kept detailed incident data that was exclusively related to platform gap related incidents. There was no consistency in the type or quality of data that was provided by the five systems. The quality, accuracy, and structure of the data limited detailed statistical analysis or comparison between systems.

The station injury incident data received from the four other transit systems (B, C, D, and E) did not have enough injury incidents related to the platform/train and platform/guideway to conduct a statistically significant analysis, however it was possible to see trends in the data that was provided. In addition, follow-up phone interviews were also conducted for clarification of some of the incident data items. All of the transit systems record the same basic information (date, time, location, etc.), however certain systems go further to record very specific data. These additional details are very useful when trying to identify trends that can lead to injuries. Transit System A provided additional details that included identification of which leg received the injury, age of passenger involved in the incident, straight versus curved platform and guideway, and measurement of both horizontal and vertical gaps. The quality of the data also depended upon who submitted the incident report and the time elapsed from the event. The length and content of the incident description section varied both between the transit systems and even within a single system. Most of the data provided only included a brief description of the incident and very limited notations were included to suggest the seriousness of the incidents and whether the incident resulted in a fatality, serious injury, or minor injury. Some of the incident data was redacted for legal reasons, and other data records did not include any information on who or what type of responder was involved or if the passengers was transported to hospital.

More common incidents include general slips and falls on the platform and falls on stairs and escalators. However, based on the data provided, platform/train and platform/guideway interface related incidents are infrequent and make up less than ten percent of the total number of passenger injury incidents.

For some of the data sets, additional data could be pulled from the description when detailed descriptions were available. Table 1 shows the system level comparisons of the five transit systems. In the table, PTI refers to the platform train interface. The data is derived from the National Transit Data base for 2013 which is the same year as the incident data [2].

Table 1. Comparison of the five systems that provided data for platform/train and platform/guideway safety incidents.

\begin{tabular}{|c|c|c|c|c|c|}
\hline Incident Rates & $\begin{array}{c}\text { Transit } \\
\text { System A }\end{array}$ & $\begin{array}{l}\text { Transit } \\
\text { System B }\end{array}$ & $\begin{array}{c}\text { Transit } \\
\text { System C }\end{array}$ & $\begin{array}{c}\text { Transit } \\
\text { System D }\end{array}$ & $\begin{array}{l}\text { Transit } \\
\text { System E }\end{array}$ \\
\hline Annual System Miles (2013) & - & - & - & - & - \\
\hline Passenger Revenue Miles & $344,975,317$ & $69,046,006$ & $75,884,600$ & $7,884,786$ & $65,652,045$ \\
\hline Train Revenue Miles & $37,908,349$ & $8,945,014$ & $11,569,883$ & $1,955,280$ & $8,945,014$ \\
\hline Unlinked Passenger Trips & $2,656,476,693$ & $229,113,934$ & $273,828,461$ & $21,198,687$ & $126,546,495$ \\
\hline $\begin{array}{l}\text { Average Number of PTI }{ }^{1} \\
\text { Incidents/Year }\end{array}$ & 161 & 72 & 1 & 9 & 42 \\
\hline $\begin{array}{l}\text { Percent PTI Incidents of Total } \\
\text { Incidents }\end{array}$ & $\mathrm{N} / \mathrm{A}$ & $8 \%$ & $5 \%$ & $4 \%$ & $15 \%$ \\
\hline Year Range for PTI Data Collected & 2013 & 2013-2014 & 2010-2013 & 2013-2014 & 2013-2014 \\
\hline $\begin{array}{l}\text { Not Otherwise Classified Injuries } \\
\qquad\left(\text { NTD 2013) }{ }^{2}\right.\end{array}$ & 5067 & 466 & 292 & 102 & 752 \\
\hline $\begin{array}{c}\text { Incidents/10 Million Passenger } \\
\text { Revenue Miles }\end{array}$ & 5 & 10 & 0 & 11 & 6 \\
\hline $\begin{array}{c}\text { Incidents/10 Million Train } \\
\text { Revenue Miles }\end{array}$ & 42 & 80 & 1 & 46 & 47 \\
\hline $\begin{array}{c}\text { Incidents/10 Million Unlinked } \\
\text { Passenger Trips }\end{array}$ & 1 & 3 & 0 & 4 & 3 \\
\hline
\end{tabular}

Notes: ${ }^{1}$ PTI Platform Train Interface; ${ }^{2}$ (NTD 2013) National Transit Database-2013. 


\section{Results}

The results are presented to two parts, Transit System A provided detailed data that focused solely on incidents at platform/train and platform/guideway interfaces, and the four other transit systems provided data on station-related passenger injury incidents.

\subsection{Transit System A}

The following is a brief summary of the data for 2013 from Transit System A.

- Majority of incidents occurred during boarding (68\%) as opposed to alighting (32\%).

Some incidents reports showed that incidents occurred when passengers stepped out of the train temporarily to provide more room for alighting or boarding passengers. For these types of incidents, the most common incident scenario occurred when the passenger initially stepped out of the train, but not while re-boarding the train.

Time of day incidents showed that a.m. and p.m. peaks were similar, and most incidents occurred at off peak times. In the incident reports, many passengers involved with gap incidents cited overcrowding or pushing as being instrumental in causing the event.

- $\quad$ A.M. Peak 22\%, P.M. Peak 28\%, and Off Peak 50\%.

There is a slight increase in incidents at platform/train interfaces during summer months (July, August, and September) but overall these injuries appear to be consistent throughout the year. The total number of platform/train interface incidents on a monthly basis can be seen in tabular form in Table 2 .

Table 2. Month of injury and number of percent of total annual injuries.

\begin{tabular}{ccc}
\hline \multicolumn{3}{c}{ Month of Injury } \\
\hline Months & Number & $\%$ \\
January & 7 & $4 \%$ \\
February & 11 & $7 \%$ \\
March & 16 & $10 \%$ \\
April & 14 & $9 \%$ \\
May & 13 & $8 \%$ \\
June & 13 & $8 \%$ \\
July & 19 & $12 \%$ \\
August & 17 & $11 \%$ \\
September & 15 & $9 \%$ \\
October & 12 & $7.3 \%$ \\
November & 12 & $7.3 \%$ \\
December & 12 & $7.3 \%$ \\
Total & $\mathbf{1 6 1}$ & $\mathbf{1 0 0} \%$ \\
\hline
\end{tabular}

- $\quad$ Majority of incidents involved female passengers (61\%) versus male (39\%).

It was discussed during the follow up interviews with the safety officers at Transit System A that female passenger may be more likely to report an incident than male passengers. Women's footwear was also suggested as a contributing factor to incidents. It was conjectured, but not explicitly described, in the data that high-heeled type footwear could have potential negative effects on a passenger's stability when boarding or alighting a train.

- $65 \%$ of the injuries occurred on platforms without any curvature and $35 \%$ occurred on platforms that had some level of curvature.

There are many more station platforms that do not have any curvature than stations with curved platforms. However, the proportion of incidents may be more common relative to total number of platforms on curved/transition platforms. 
- $67 \%$ of the injuries were adults, $25 \%$ were children, and $8 \%$ were elderly.

During the follow up interviews, the respondents from Transit System A indicated that these percentages are not reflective of the general age demographic profile of the transit system. The percentage of children and elderly injury incidents represent a higher proportion of the overall population of passengers.

\subsection{Transit Systems $B, C, D$, and $E$}

Injury incident data was obtained from four other transit systems that operate heavy rail transit. The content and details included in the incident data was highly variable. The data provided was not compiled in a consistent format and there was a large variation in the quality of the data. Table 3 is an aggregate summary in number and percentages of the injury incident data that was derived from the data provided. With the exception of transit system E, stair and escalator injuries were the most common. All transit systems reported higher levels of slips and falls.

Table 3. Number and aggregate percentages for transit systems B, C, D, and E.

\begin{tabular}{ccccc}
\hline \multirow{2}{*}{ Incident Type } & Transit System B & Transit System C & Transit System D & Transit System E \\
\cline { 2 - 5 } & No. (\%) of Total & No. (\%) of Total & No. (\%) of Total & No. (\%) of Total \\
\hline Closed in Door & $31(4 \%)$ & $19(20 \%)$ & $9(3.7 \%)$ & $69(25 \%)$ \\
Slipped and Fell & $275(33 \%)$ & $14(14 \%)$ & $58(23.8 \%)$ & $107(39 \%)$ \\
Gap/Platform interfaces & $73(8 \%)$ & $5(5 \%)$ & $9(3.7 \%)$ & $42(15 \%)$ \\
Intoxication & $32(4 \%)$ & $4(4 \%)$ & $4(1.6 \%)$ & $5(2 \%)$ \\
Injuredby Escalator/Stairs & $352(41 \%)$ & $52(54 \%)$ & $159(65.2 \%)$ & $10(4 \%)$ \\
Attempted or Successful Suicide & $2(0.2 \%)$ & $3(3 \%)$ & $0(0 \%)$ & $0(0 \%)$ \\
Involved Wheelchair & $7(0.8 \%)$ & $0(0 \%)$ & $3(1.2 \%)$ & $10(4 \%)$ \\
Struck by Train & $0(0 \%)$ & $0(0 \%)$ & $2(0.8 \%)$ & $7(3 \%)$ \\
Fell into Guideway/Right-of-Way & $79(9 \%)$ & $0(0 \%)$ & $0(0 \%)$ & $22(8 \%)$ \\
Total & $\mathbf{8 5 2 ( 1 0 0 \% )}$ & $\mathbf{9 7}(\mathbf{1 0 0} \%)$ & $\mathbf{2 4 4}(\mathbf{1 0 0} \%)$ & $\mathbf{2 7 2}(\mathbf{1 0 0} \%)$ \\
\hline
\end{tabular}

\subsubsection{Transit System B}

Transit System B provided data that included general platform incident data from November 2013 through early October 2014. Transit System B reported platform gap related incidents in terms of both number and proportion to other incident types on the system. Of the 852 total incidents, 73 involved the platform train incidents. The incident reports show that people fell or slipped into the gap between the train and platform rather than tripping over the gap. Upon further analysis, it appears that over 50 percent of the platform incidents occur on one single line that has underground, at grade, and elevated stations.

At Transit System B the majority of the incidents occur during the daytime (9 a.m. to 4 p.m.) followed closely by the p.m. Peak period that was designated as trips between 4 p.m. and 7 p.m. The data showed that men and women were equally as likely to be injured due to a platform incident but 25 percent of the incident reports did not specify a gender.

Forty-one percent of the injury incidents reported by Transit System B were injuries sustained on escalators or staircases and general slips or falls on the platform not related to boarding or alighting or the platform train gap accounted for 33 percent.

One unique characteristic of the incident data provided by Transit System B was the number of passengers who fell into the guideway. It was the third most common incident that occurred within the dataset. Despite the high number of guideway intrusions, there appeared to be no passengers struck by a train and none were listed as successful suicides or attempted suicides.

Transit System B incident data showed that 4 percent of the incidents involved passengers, getting caught in the train doors while boarding or alighting. It was also reported that 4 percent of the incidents identified that alcohol played a significant role. 


\subsubsection{Transit System C}

At Transit System C, 54 percent of the platform incidents involved injuries from escalators or stairs. Based on the incident descriptions, slips and falls appear to be related to platform conditions whether they are environmental (wet, icy, etc.) or physical condition (uneven pavement, cracks, etc.). Of the reported type incidents at Transit System C, only one involved a passenger who got stuck between the platform and train. The remaining injuries involved tripping or falling while exiting or entering the train. Passengers getting struck by the door or caught during the door-closing phase were 20 percent of the incidents. Door closing regimes may contribute to platform/train interface injuries. When the doors are closing and a passenger wishes to board or alight the train the focus is diverted from where the passenger is stepping to avoid the closing doors, and this is could cause a passenger to trip over or fall into the gap between the train and platform.

\subsubsection{Transit System D}

Transit System D provided data on platform/train and platform/guideway that involved incidents on the rail systems in which they operate from August 2013 to August 2014. Consistent with Transit System C, Transit System D reported that 65 percent of the injury incidents involved escalators or stairs. The incident reports showed that elderly females were most likely to be involved in stair and escalator incidents. Transit System D showed that 24 percent of the injuring incidents were slips and falls on the platform or inside the train during braking. The majority of the platform related slips and falls were attributed to the environmental or platform condition. Transit System D only reported that 4 percent of the injury incidents involved closing of the doors and only one passenger physically got caught between the train and platform.

\subsubsection{Transit System E}

The Transit System E data showed that slips and falls accounted for 39 percent of the injury incidents, and that these occurred most often when passengers were alighting.

Twenty-five percent of the injury incident types reported were passengers getting caught in closing doors, and the reports showed that more passengers got struck by the doors when they are alighting. The incident data showed that 15 percent of the incidents involved the platform/train and platform/guideway interfaces. Transit System E reported that 8 percent of the injury incidents involved passengers who fell into the guideway or right of way, however crowding or pushing were not listed as factors.

\subsection{Summary of Trends in the Incident Data}

The incident data from all the participating transit systems showed some common trends. Escalators and stairs are a source of many of the injury incidents. General slips and falls on the platform or within the train are far more common than platform/train and platform/guideway incidents.

The most common platform/train interface incident injury involves falling while boarding or alighting from the train. Injury incidents involving passengers and train doors were also common. Rail transit systems have different ways of reporting attempted or successful suicides, and most often they are treated as trespass events. Rail transit systems also have different reporting strategies for intoxication.

Common passenger incident reporting protocols and standards for rail transit agencies including commuter rail would improve data analysis of passenger incidents on the platform and in the station.

\section{Discussion}

Rail transit safety at the platform/train or platform/guideway interfaces are impacted by the characteristics of the rail transit modes. Heavy rail transit systems that often have high level 
platforms had a greater number of injury incidents than light rail which often operates on lower level platforms.

\subsection{Heavy Rail Transit}

Heavy rail transit operates on exclusive right of way that is fully grade separated from the street network. Heavy rail transit stations have high-level platforms, and accommodate trains that are more than four cars in length. High level platforms are platforms that are over two feet from top of rail and most are over three feet from top of rail. Heavy rail transit is almost always electric powered by either overhead catenaries or a high voltage third rail. In order to comply with the Americans with Disabilities Act, urban rail systems that have been constructed since 1991 have small horizontal and vertical gaps between the train and platform that are attributable to platform and train design attributes.

Interviews with urban rail transit systems indicated that the common incidents tend to be general slips and falls on the platform not related to the platform/train and platform/guideway interface. With the exception of Transit System A, the other rail transit systems reported or documented very few incidents at the platform/train and platform/guideway interfaces. However, other types of safety incidents such as trips or falls on stairs and escalators or incidents related to contact of the side of the train were reported. There were reported injury incidents that were related to passengers coming in contact with closing doors, and coming in contact with the side of the train as the train accelerated out of the station.

\subsection{Light Rail and Streetcars}

Most of the modern light rail transit and streetcar transit systems have low-level platforms that are 14 inches above the top of rail for approximate level boarding with low floor trains. Many of the older light rail systems have high floor trains with on board steps, or some have high level platforms and share many of the characteristics of heavy rail transit. The respondents who operated light rail transit systems reported that there are very few injury incidents associated with the platform/train or platform/guideway interface. However, there were other types of injury incidents that resulted from people sitting on the edge of the platform. Several light rail transit systems reported injury incidents due to people crossing through the guideway from one platform to another despite posted placards warning people not to do this.

\subsection{Other Factors that Contribute to Injury Incidents}

A number of factors contribute to injury incidents that are not specific to a particular mode of rail transit, and these include; train door design, intoxication and suicides, footwear, distracted passengers, pushing and crowding, and wheelchair incidents.

\subsubsection{Rail Transit Train Door Design}

The main issues raised by the rail transit train manufacturers that were interviewed were related to the door design. Interviews of the rail transit train manufacturers indicated mixed reactions with the requirement for the passenger door to remain shut when deploying a ramp, or bridge plate. Two of the vehicle manufacturers indicated that not requiring the door to be closed during deployment would reduce dwell times, however the other train manufacturers were supportive of the current requirement. Transit systems interviewed also emphasized the safety concerns associated with allowing the doors to be open during ramp deployment. In the transit system interviews it was suggested that even if door open operation was available, the transit system would not utilize this feature.

The American Public Transportation Association Standard for Powered Exterior Side Door System Design for new Passenger (Train) Cars, provides the minimum requirements for powered exterior side door systems [3]. There were at least two train manufacturers that mentioned design elements concerning the sensitive edge on the door to prevent people being caught in the doors. There are interlock systems that permit passengers to manually push the doors 2 to 3 inches apart and this 
automatically prevents the train from moving. Other door edge systems are called "leash sensitive" and these systems are designed to prevent people with service animals having the animal and person on opposite sides of the door.

\subsubsection{Intoxication and Suicides}

Intoxicated passengers have significantly higher accident rates as compared to the general population. According to the Rail Safety and Standards Board study, males are more than twice as likely to be involved in a boarding or alighting accident, and other types of incidents while intoxicated. In the British report, approximately 6 percent of the overall boarding and alighting incidents involve intoxicated passengers, and these incidents are most likely to occur Thursday through Saturday evenings with a peak at 11 p.m. The data showed that between the hours of 9 p.m. and 12 a.m. the accident rate involving intoxicated passengers is twice that of sober passengers [4].

The researchers at Tokyo University of Science also found intoxication to be a significant factor contributing to platform injury rates. In fact, it was one of the highest weighted variables present in their model on platform safety [5].

The Bangkok Mass Transit System also recognized the potential safety issues caused by intoxicated passengers. According to the findings from a passenger survey, the majority of people suggested that they thought intoxicated passengers should not be allowed to ride the trains [6]. This is contrary to many of the "designated driver programs" that are provided by North American transit agencies.

Incidents related to suicides and intoxicated passengers were significant concerns during transit system interviews across all modes of rail transit operations. These incidents included people falling on to the guideway either intentionally or accidentally. This type of incident was reported in all the data sets that were analyzed. The frequency was very low, but the costs of each fatal injury incident in terms of operator stress and lost travel time are very high.

A number of transit systems have conducted research projects on the use of platform edge protection systems as a possible mitigation strategy [1]. Several transit systems have placed placards that list the suicide crisis line phone number at platform edges and grade crossings [1]. A number of transit systems are conducting active suicide prevention campaigns through information on their websites and public outreach programs. It is important to note that according to the data received by the five different agencies, suicide does not appear to be very prevalent. However, when consideration is given to the cost to both the transit system and those passengers and employees involved, the issue is still important. Universally, the transit systems do not publicize these types of incidents in order to reduce 'copycat incidents' and have developed management plans to manage service interruptions caused by these incidents.

\subsubsection{Passenger Age}

The age of the passenger is a factor reported in both the New Jersey Transit study and the Rail Safety and Standards Board studies [4,7]. Findings from both investigations seem to suggest that there is a significant difference in incident rates based on passenger age.

The Rail Safety and Standards Board study focused on passengers of less than 16 years of age. This study, conducted in Great Britain, found that young transit riders had a higher incident rate proportional to the number of total passengers in that category [4]. The New Jersey study divided the ages down into more categories and put children under the age of 10 and the 10-20 year old segment into separate categories. According to the New Jersey study results, children under the age of 10 were at a very high risk for a boarding or alighting gap incident. However, the percentage of injured was reduced for those in the 10-20 year old category. Based on the data presented from both studies, it can be concluded that children have a higher risk for platform incidents [7]. Both studies cite reasons such as size, physical capabilities, distraction, and lack of experience with transit as possible reasons. 
Older transit passengers have a very high number of incidents relative to the number of total travelers. Both the New Jersey and British studies found that people over the age of 50 had a significantly higher rate of platform incidents as compared to middle-aged passengers. The Rail Safety and Standards Board study found the over 50 year old age category to have the highest magnitude of gap related incidents [4]. The New Jersey Transit Study also found this age group to have the most platform incidents [7].

\subsubsection{Footwear and Gender}

None of the injury incident data that was provided included enough detail on passenger footwear. In the interviews with safety officers from rail transit systems, several of the respondents indicated that women's footwear such as high heels could be contributing factors, but this was not documented specifically in the incident reports and the data analysis was not able to support or refute these observations.

Female passengers tend to have a higher risk of injury for gap related incidents according to the New Jersey and Rail Safety and Standards Board studies as well as the analysis of incident data from a specific transit agency. Table 4 shows the data from the three sources. This data is relatively consistent. It has been suggested that one of the possible reasons for higher representation of females is that women are more likely to report a platform incident [4]. Additional reasons mentioned by the New Jersey study involved women pushing strollers and the distraction of small children.

Table 4. Comparison of female involvement in reported injury incidents.

\begin{tabular}{cc}
\hline Source & \% of Females \\
\hline New Jersey (4) & 69 \\
UK Study (5) & 63 \\
Transit Agency & 61 \\
A Incident data & \\
\hline
\end{tabular}

Women's footwear was one of the reasons cited for women having an increased injury rate $[4,7]$. Specifically, the British study suggested that women wearing high-heeled shoes contribute to instability while boarding or alighting [4]. However, the factors pertaining to children and footwear were determined to have a small overall effect during the observational studies [7].

\subsubsection{Distracted Passengers}

The safety officers from rail transit systems that were interviewed indicated that distracted passengers who are texting and talking on cell phones may contribute to platform injury incidents, however the injury incident reporting forms currently used by the transit systems do not document passenger distraction.

Cellphones and MP3 players have essentially made many passengers blind and deaf according to a study on intrusion prevention technology. These distractions greatly affect people's ability to recognize an approaching train or judge a gap distance [8]. The New Jersey study did not find cellphone use to be highly significant based on people talking on the phone because of excessive noise on the platform [7].

Since the New Jersey report was published, The Wireless Association, conducted a survey in 2016 and reported that smart phone market share has more than tripled from December of 2009 through December of 2016 [9]. The primary distraction measure for a smart phone would likely not be a phone conversation but rather texting, email, Internet, music, or application use.

Research has not been conducted on the relationship of cell phone use and platform train interface safety, but it may be reasonable to conclude that cellular telephone use will increase the likelihood of possible injury due to distraction. 


\subsubsection{Pushing and Crowding}

The injury incident data did indicated directly that pushing and crowding were contributing factors to injury incidents. Many of the incident descriptions documented over- crowding or pushing but there is no consistent measure that defines "pushing or crowding".

Passenger crowding can impact boarding and alighting safety. As noted by Hulse, platform congestion can vary significantly from location to location. Cultural variations can also influence whether passengers form orderly lines on the platform or tend to cluster near to the door locations. Higher levels of congestion were determined to increase injury possibilities at the platform-train-interface [8]. Crowded conditions are often seen on the Bangkok Mass Transit System, particularly at transfer stations during the morning and evening peak times. Based on passenger surveys, crowded platforms were seen as a significant factor that contributes to injuries in stations [6]. Crowding was also found to have a large negative effect on safety in Japanese railway stations [5].

The boarding and alighting experiment conducted at Delft University of Technology looked at passenger crowding characteristics as it related to dwell times. Intuitively, as the density of passengers increased on both the train and platform, the speed in which they were able to board or alight decreased [10]. The Federal Railroad Administration report on Managing Gap Safety also concluded that as the level of crowding increased, so did the risk of a gap-related incidents. This was found to be true for those stations with well managed gaps as well as those platforms that suffered from excessive gaps [11].

\subsubsection{Wheelchair Incidents}

There were sporadic incidents across all the incident data sets of people in wheelchairs falling on to the guideways. There were no trends in the data, however, it was reported during an interview with one transit agency that in one incident the passengers lost control of their wheelchair and this contributed to the incident.

\subsubsection{Time of Incident}

The transit agencies have different definitions of peak and off peak times. The New Jersey study defined the a.m. peak from (7 a.m.-10 a.m.), mid-day (10 a.m.-3 p.m.) and p.m. Peak (4 p.m.-7 p.m.) and p.m. non peak (7 p.m.-12 a.m.). By gender, incidents involving men were more likely to occur throughout the day with a slight peak in the p.m. and p.m. non-peak hours. Incidents involving women were more likely to occur during the a.m. and p.m. peak [7].

The report published by Rail Safety and Standards Board also had results concerning time of day and incidents. These findings however were not broken down by age and gender. Interestingly, the results from the report suggest that the incident rates are highest in the off peak times of day (midday) and the p.m. peak [4]. This was also seen in the data from Transit systems A and B where most of the incidents occurred on off peak hours. There is a small increase in injuries at 8 a.m. The early morning peak differs from the New Jersey study and it suggests that the peak periods do have increased risks for injuries. From both studies, it appears that the number of injuries is somewhat consistent throughout the week and decreases on the weekends quite dramatically $[4,7]$. This seems to make sense as there are far fewer travelers on rail transit vehicles on the weekends.

\section{Conclusions}

The injury incident data collected from the five rail transit systems showed that stairs and escalators and general platform tripping produced more injury incidents than the platform/train and platform/guideway interfaces. Heavy rail transit with platforms that are higher than 24 inches had more injury incidents than light rail transit that typically operates on low level platforms that are about 14 inches high. Other causes of injury incidents included intoxication, attempted suicide, and distraction. 
Transit System A provided detailed platform/gap injury incident data, but still there were variations in the quality of data due to when and who made the reports. A common injury incident reporting scheme for all rail transit agencies and one that includes more detail than is currently required for FTA or FRA reporting is needed. This would improve the comparison and analysis of injury incidents and successful mitigations of many of the injury incidents would improve rail transit safety for all.

Acknowledgments: The research reported was conducted as part of the Transit Cooperative Research Program (TCRP) Project A-40 Manual to improve safety a platform/train and platform/track interfaces. No funds have been received to publish in open access.

Conflicts of Interest: The TCRP A-40 project panel provided direction for the collection, analyses or interpretation of data. They did not contribute to the decision to publish the results.

\section{References}

1. Hunter-Zaworski, K.; Rutenberg, U.; Anderson, D. Manual to Improve Safety a Platform/Train and Platform/Track Interfaces; Report Number 189; National Academies, Transportation Research Board: Washington, DC, USA, 2017.

2. National Transit Database. Available online: https://www.transit.dot.gov/ntd (accessed on 2 August 2016).

3. American Public Transportation Association. Standard for Powered Exterior Side Door System Design for New Passenger Cars; APTA PR-M-S-18-10; APTA: Washington, DC, USA, 2011.

4. Passenger Risk at the Platform-Train Interface; Rail Safety and Standards Board (RSSB): London, UK, 2011.

5. Yamada, S.; Terabe, S.; Kasai, M. Safety performance measures for railway stations. In TRB 93rd Annual Meeting Compendium of Papers; No. 14-1868; Transportation Research Board of the National Academies: Washington, DC, USA, 2014.

6. Santoso, D.S.; MahadthaI, S. How Safe is the Rail Platform? A Study of Bangkok Mass Transit System (BTS). Eastern Asia Society for Transportation Studies. Available online: http:/ / easts.info/on-line/proceedings/ vol9/PDF/P233.pdf (accessed on 14 July 2017).

7. Daniel, J.R.; Rotter, N.G.; Nichnadowicz, V.F. Customer Behavior Relative to Gap between Platform and Train; New Jersey Institue of Technology: Newark, NJ, USA, 2009; pp. 1-79.

8. Hulse, J. Intrusion detection and prevention technologies available to rail transit. In Proceedings of the 2013 APTA Rail Conference, Philadelphia, PA, USA, 2-5 June 2013.

9. CTIA's Wireless Industry Annual Survey 2016. CTIA-The Wireless Association. Available online: http:/ / www.ctia.org/your-wireless-life/how-wireless-works/annual-wireless-industry-survey (accessed on 14 July 2017).

10. Daamen, W.; Lee, Y.; Wiggenraad, P. Boarding and alighting experiments: Overview of setup and performance and some preliminary results. In Transportation Research Record: Journal of the Transportation Research Board; No. 2042; Transportation Research Board of the National Academies: Washington, DC, USA, 2008; pp. 71-81.

11. FRA Approach to Managing Gap Safety. US Department of Transportation, Federal Railroad Administration Office of Safety, 7 December 2007. Available online: https://www.fra.dot.gov/eLib/Details/L03196 (accessed on 14 July 2017).

(C) 2017 by the author. Licensee MDPI, Basel, Switzerland. This article is an open access article distributed under the terms and conditions of the Creative Commons Attribution (CC BY) license (http:/ / creativecommons.org/licenses/by/4.0/). 